taminated ? I could only account for this on the supposition of absorp. tion by the milk of fever-particles from the atmosphere of the premises. The privy and house-drainage flowed on to the surface to join a semiliquid manure-heap close to the stable where the cows were kept and milked; and probably the warm fresh-drawn milk proved an attractive pabulum for the fever-particles, which, it could be easily conceived, might be given off from the reeking mass of filth already clescriberl. Against this theory, cloubtless, may be advanced the argument, that enteric fever is not, like typhus and relapsing fevers, often conveyed from the sick to the healthy by atmospheric influence; but may not this arise from the fact of the poison being contained chiefly in the faces, the offensive character of which causes their quick removal from the sick room?

I remember, aniongst other instances, the case of a fruiterer's girl who had been strictly kept to attend the shop, whilst her mother tended a fever-afflicted boy segregated in an upper room of the house. The girl remained perfectly well until one day, on an emergency, she went to the sick room to assist the boy from a night-commode. The ofiensive olour brought on vomiting, and from that time she sickened and went through a well-marked course of the disease. Joth the mother and girl emphatically dated the commencement of the illncss from the time she entererl once, and only once, the sick room as above narrated. The period of incubation was herc of the shortest possible duration, but not, I believe, without parallel.

If, however, the particles of enteric fever poison can thus be conveyed as air-borne particles, if they can accompany sewer-gases in a likc manner, what difficulty is there in assuming that milk (an article most susceptible of atmospheric influences, such as electrical disturbance, possessing, moreover, the property of becoming rapidly impregnated with the characteristic taints of surrounding substances) should attract and form a genial soil for the floating virts of this fever?

If this point be conceded, water, as an intermediate vehicle, need not always be considered such an essential element in the connecting chain of propagation as some appear to imagine, and the question may fairly be raised, which of the two media acts most frequently the part of a carrier between enteric fever evacuations and milk-air or water?

\section{EMBOLISM OF CENTRAL ARTERY OF RETINA.}

\section{By PRIESTLEY S.IITH, Esq., Birmingham.}

TIIE subject of the following case was, at the time of the occurrence, an out-patient of the Birmingham General Ilospital on account of clisease of the heart, uncler the care of 1)r. Russell. 'Through Dr. Russell's permission, I had the opportunity of keeping the case long under observation, and of cxamining the eye after ileath.

Charles ' 1 ., aged 58, coach-builder, came to the leye Hospital on June 4 th, 1873 , complaining of blindness of the right eye. The following is extracted from the notes of the case. Seven clays previously, while sitting quictly in his chair, he felt, as he believed, the right eyclid close over the cyc. Putting his finger to it, he found, to his astonishment, the eyelids open. The sight of the eye was entirely gone. He folt no pain, headache, or giddiness, either at the time or since. The losis of sight was, he says, quite instantaneous. The eye harl no perception of light since. The movements of the globe, and the extcrnal appearance were normal. The pupil was of medium size; it did not respond to light; it acted in association with its fellow. Vision was absolutely lost in all parts of the retina. The media were clear. The disc, especially its margin, was much obscured by a white hay halo. The retina was rather hazy throughout, but much more so around the disc than at the equator, where the choroidal plexus was just discernible. The situation of the macula lutea was marked by a clark reddish dot, sur. rounded by a white hazy halo, which shaded off gradually into the recl of the surrounding region. The retinal arterics were pale, and reduced (n) very fine lines, visible only on careful examination. The retinal veins were somewhat below the normal size, and presented the following ap. pearance. Each of the two primary trunks, as it emerged from the disc, was of about half the natural size; passing outwards, it increased considerably up to its first bifurcation ; each of the branches arising here began as a very fine trunk, and then, in like mamner, graclually increased in size up to the next point of division. The next branches did the same, and so on throughout; so that the whole venous system of the retina, instead of gradually lessening in diameter from the disc towards the equator, as in the natural state, presented a series of reversed en. largements and sudden diminutions. The point of maximum size was, in every instance, just on the discal sicle of a bifurcation. Upon the white halo around the macula lutea, the ultimate venous ramifications stoml out in a striking mammer. The left eye appeared sound in every way. The patient had a loud double aortic murmur, the systolic portion being almost musical in character. He had rheumatic fever a year ago, and believed he had had previous attacks also.

On June 23rd (twenty-six days after the occurrence), but little effusion remained in the fundus. The retina was clear; the choroidal plexus was every where clearly seen. The disc was whiter than at first; still rather ill defined, though much clenrer than before. Some whiteness still remained around the macula lutea in the form of a double zone, the inner closely surrounding the central dot, the outer separated from this first by an almost complete ring of clear red. 'The veins were smaller than before at the disc, but a little larger than the arterics; at the equator rather larger than at the disc. There was no appearance of collateral circulation. He had no perception of light.

On August 12th (cleven weeks after the occurrence), the disc was very white, the fibrous stroma clearly seen. The arteries were very fine, but distinctly visible; the veins rather larger than the arteries, especially at the equator. The macula lutea was harclly to be distinguished. IIe had no perception of light.

Just four months after the loss of sight, the patient died in the General Ilospital. The aortic valves were found to be the seat of very extensive disease. Two of the valves were fused together into a thick unyiclding warty mass. The third valve retained some mobility, but was also much thickened and studded with excrescences. The right optic nerve was found to be somewhat shrunken throughout the whole of its length. A transverse section of the nerve, immediately behind the globe, showed, under the microscope, that the central vessels had unclergone marked changes. The vein was patent, but much smaller than that found in the average healthy nerve. Unfortumately, I had not thought of removing both nerves for the purpose of comparison until too late. The artery, as a tube, was no longer in existence; its former position was, however, clearly indicated by a well dcfined circular mass of concentrically arranged fibrous tissue adjacent to the vein.

\section{OBSTETRIC MEMORANDA.}

\section{TREATIENT OF POST PARTUM HAMORRILAGE,}

Xir.

THF means of suppressing post purtum hæemorrhage have been most ably discussed in the pages of the Jot'R.A.AL; but I think scarcely enough attention has been paid to the means for its prevention.

Although I never had a fatal case, yet, in my early practice, it was my lot to meet with two very alarming ones. Subsequently, I noticed that, although there might be no large loss of blood, the sudden evacuation of the contents of the uterus, especially when there was a large quantity of liquor ammii, was often followeel by death-like faintness. Even in tapping for ascites, it is alway's laicl down as a rule to apply a bandage, which is gradually tightened as the fluid cscapes, to assist the abdominal muscles, and to compensate in some measure for the loss of pressure sustained by the large vessels and viscera of the ablomen. If, then, such precautions are necessary in a casc where the evacuation of the fluid is entircly under control, why should not similar precautions be taken in the emptying of the uterus? Most practitioners, no cloubt, apply a binder, but not till the uterus has cmptied itself, and the large blood-vessels of the abdomen have become turgid with blood from want of that support to which they have for months been accustomed. I was led by such considerations to adopt the plan of using the binder, not only after, but during labour; and, as since then 1 have not had a single case of post partum hamorrhage, or even of that sulden exhaustion which I had before so often witnessed, I am induced to describe the plan which I adopt uniformly in all labours, and which I have found successful.

I select some stout material, wide enough when doubled to reach from the funclus of the uterus to two or three inches below the crista ilii. This, as soon as the woman is confined to her bed, is pinned as tightly round her as ean be borne, thus giving support to the abdominal muscles, and keeping the child in the axis of the pelvis. As soon as true expulsive pains commence, the binder is unpinned, and the upper fold griven into the hands of the nurse, with the directions that, during each pain, she should draw it as smoothly and tightly as possible acrois the patient's alylomen. There is no fear of the lower fold slipping, as it is kept in position by the weight of the woman's body, and therefore should be left quite alone. As soon as the head begins to emerge beneath the pubes, the pressure should be continuous and as strong as possible, and ncver relaxed for a single instant till after the child is born and the placenta expelled, when the binder should be pinned as tightly as possible by the surgeon himself, and not left, as is ton often clone, to the nurse. 